\title{
PERFIL DE ÁCIDOS GRAXOS NO ÓLEO EXTRAÍDO DAS FARINHAS DOS CAROÇOS DE JACA (Artocapus integrifólia L.), ABACATE (Persea Gratíssima Gaertner F.) E SERIGUELA (Spondias Purpúrea L.)
}

\author{
M. R. F. NASCIMENTO', V. F. de $\operatorname{SOUZA}^{2}$, L. de Q. BOMDESPACHO ${ }^{3}$ e J. L. R. \\ ASCHERI $^{4}$ \\ ${ }^{1,2}$ Universidade Federal Rural do Rio de Janeiro, Departamento de Tecnologia de \\ Alimentos \\ ${ }^{3}$ Universidade de São Paulo, Faculdade de Zootecnia e Engenharia de Alimentos \\ ${ }^{4}$ Embrapa Agroindústria de Alimentos do Rio de Janeiro \\ E-mail para contato: vssouzafrana@gmail.com
}

\begin{abstract}
RESUMO - Os resíduos dos caroços de jaca, abacate e seriguela, podem ser alternativas de uso como fontes de óleos. O objetivo deste estudo foi determinar a extração do óleo de farinha dos caroços de jaca (Artocapus integrifólia L.), abacate (Persea Gratíssima Gaertner F.) e seriguela (Spondias Purpúrea L.) e caracterizá-los quanto ao perfil dos ácidos graxos. Dessa farinha foram analisados: extração do óleo, derivatização do óleo e análise cromatográfica dos ésteres metílicos. No caroço de abacate predominaram os ácidos graxos saturados com $65 \%$, e o ácido graxo palmítico com 48,22\% e o teor de ácido graxo insaturado foi de $34 \%$. No caroço de jaca e seriguela, os ácidos graxos insaturados apresentaram as maiores porcentagens, 60 e 50\%, respectivamente. Ambos caroços apresentam como principal ácido graxo insaturado o ácido linoléico (ômega-3) essenciais para a alimentação humana. Concluí-se portanto, que o aproveitamento desses coprodutos podem ser uma alternativa na agroindústria de alimentos, pela sua qualidade nutricional aplicandose em formulações como forma de agregar valor.
\end{abstract}

\section{INTRODUÇÃO}

Os ácidos graxos essenciais para a alimentação humana são ácido linolênico (ômega-3) e o ácido linoléico (ômega-6). O primeiro está presente em grande quantidade nos óleos de milho e soja, enquanto o segundo, em vegetais de folhas verdes, no óleo de linhaça e nos óleos de peixes marinhos. A importância destes ácidos graxos está na sua capacidade de se transformar em substâncias biologicamente mais ativas, com funções especiais no equilíbrio homeostático, e em componente estrutural das membranas celulares, e do tecido cerebral e nervoso. A alimentação humana corretamente balanceada deve atender a uma relação ótima entre ômega-6 e ômega-3, de 4:1, porém o ritmo de vida atual muitas vezes não permite uma alimentação rica e bem combinada, baseada em alimentos criteriosamente selecionados (TAKAHASHI, 2005).

O consumo e os benefícios da ingestão de ácidos graxos poli-insaturados vêm sendo estudados e constatando-se efeitos fisiológicos importantes em humanos na 
prevenção e no tratamento de muitas doenças (WARD, 1995; MAYSER, 1998; SANDER, 2000).

Neste estudo sob o aspecto nutricional dos frutos, destacam-se: a seriguela que apresenta um conteúdo elevado de amido, sendo possível perceber, em alguns casos, o sabor amiláceo na fruta fresca (FILGUEIRAS, MOURA e ALVES, 2000). A jaca não somente os bagos são comestíveis e nutritivos como seus caroços, que são compostos de nutrientes de excelente quantidade e qualidade tanto ou mais que em sua polpa (MELO et al, 2006). O abacate possui ácidos graxos insaturados (ácido oléico), substância que pode reduzir doenças cardiovasculares (ROCHA et al, 2005). Além disso, neste fruto as vitaminas lipossolúveis são muito bem representadas, já que geralmente não estão presentes em outras frutas (NURAY et al, 2005).

O objetivo deste trabalho foi determinar a extração do óleo de farinha dos caroços de jaca (Artocapus integrifólia L.), abacate (Persea Gratíssima Gaertner F.) e seriguela (Spondias Purpúrea L.) e caracterizá-los quanto ao perfil dos ácidos graxos.

\section{MATERIAL E MÉTODOS}

Os frutos jaca (Artocapus integrifólia L.), abacate (Persea Gratíssima Gaertner F.) e seriguela (Spondias Purpúrea L.) foram adquiridos da safra 2012 da CEASA Central de Abastecimento Sociedade Anônima, Município do Rio de Janeiro, pertencente ao Estado do Rio de Janeiro. Os experimentos foram realizados no Laboratório de Alimentação e Nutrição do Departamento de Economia Doméstica e Hotelaria (DEDH) da Universidade Federal Rural do Rio de Janeiro-UFRRJ, localizada no município de Seropédica. A análise de composição em ácidos graxos foi conduzida na Embrapa Agroindústria de Alimentos, localizado em Guaratiba, Rio de Janeiro, RJ.

\subsection{Análises físicas}

Os frutos jaca, abacate e seriguela aplicados neste estudo foram selecionados um a um, considerando os aspectos visuais, firmeza e ausência de perigos físicos e biológicos.

Obtencão dos carocos de jaca, abacate e seriguela- Os frutos foram pesados e lavados, compreendendo as etapas de pré-lavagem, lavagem e desinfecção. Os frutos foram imersos em água clorada a 200 ppm durante 20 minutos e enxaguados em água corrente. Em seguida foram descascados e despolpados, obtendo-se os caroços. Os caroços jaca, abacate e seriguela, logo após a obtenção, foram lavados em água corrente para a retirada dos resíduos de polpa e posteriormente submetida à secagem em um desidratador com circulação de ar a $60^{\circ} \mathrm{C}$, marca Pardal, por 10 horas, para os caroços de jaca e 8 horas para os caroços de abacate e seriguela. Parcialmente secos foram transformados em farinha com auxílio de moinho de facas e martelos com peneira de 1 mm, moinho de discos com abertura de $2 \mathrm{~mm}$, marca Laboratory Mill 3600 e moinho Perten $1680 \mathrm{rpm}$ com $0,8 \mathrm{~mm}$, que resultou em uma farinha. Em seguida, armazenadas em vidros, sob congelamento a $-10^{\circ} \mathrm{C}$.

Caracterizacão do óleo dos carocos de jaca, abacate e seriguela por meio de análises físico-químicas 
Extracão do Óleo-A determinação dos lipídeos foi realizada pelo método de BLIGH e DYER (1959), onde a extração da porção lipídica foi realizada a temperatura ambiente e proteção da luz. Essa metodologia utiliza uma mistura de três solventes, diclorometano, metanol e água na proporção de 2:1:0,8. Para cada determinação em 100 $\mathrm{g}$ da amostra, adicionados de $40 \mathrm{~mL}$ de diclorometano, $20 \mathrm{~mL}$ de metanol, $16 \mathrm{~mL}$ de água destilada, 3 minutos de agitação adicionou mais de $20 \mathrm{~mL}$ de diclorometano, 20 $\mathrm{mL}$ de água destilada. Após 3 minutos de agitação procedeu-se a filtração em filtro qualitativo de papel em presença de sulfato de sódio anidro. $\mathrm{O}$ filtrado foi transferido par funil de separação e a parte inferior (diclorometano + lipídio) foi recolhida em balão volumétrico e guardada em congelador, para posterior análise.

\section{Perfil dos ácidos graxos em duas etapas}

Derivatizacão do Óleo -A derivatização é a transformação dos ácidos graxos em ésteres (moléculas menores) obtidos segundo HARTMAN e LAGO (1973) e adaptado por MAIA (1992).

Análise Cromatográfica dos Ésteres Metílicos- Composição em ácidos graxos foi realizada por cromatografia de acordo com a metodologia AOCS, 2009. A análise foi realizada em cromatógrafo gasoso capilar (Agilent 68650 SERIES GC SYSTEM, coluna capilar: DB-23 AGILENT (50\% cyanopropil-methylpolysiloxane), dimensões $60 \mathrm{~m}$, diâmetro interno: $0,25 \mathrm{~mm}, 0,25 \mu \mathrm{m}$ filme, nas seguintes condições cromatográficas: fluxo coluna $=1,00 \mathrm{~mL} / \mathrm{min}$; ; velocidade linear $=24 \mathrm{~cm} / \mathrm{seg}$; temperatura do detector: $280^{\circ} \mathrm{C}$; temperatura do injetor: $250^{\circ} \mathrm{C}$; temperatura do forno: $110^{\circ} \mathrm{C}-5 \mathrm{~min}$; $110-215^{\circ} \mathrm{C}\left(5^{\circ} \mathrm{C} / \mathrm{min}\right), 215^{\circ} \mathrm{C}\left(5^{\circ} \mathrm{C} / \mathrm{min}\right), 215^{\circ} \mathrm{C}$ - 24 min.; gás de arraste: hélio; volume injetado: $1,0 \mu \mathrm{L}$.

\section{RESULTADOS E DISCUSSÃO}

Os resultados dos diferentes perfis em ácidos graxos dos óleos dos caroços estão apresentados na Tabela 1.

No que diz respeito as farinhas dos óleo dos caroços estudadas, pode se observar na (Tabela 1) que o caroço de abacate predominou os ácidos graxos saturados com $65 \%$, sendo que o ácido graxo palmítico apresentou maior concentração $(48,22 \%)$. E o teor de ácido graxo insaturado foi de $34 \%$. No caroço de jaca e seriguela, observa-se que os ácidos graxos insaturados apresentaram as maiores porcentagens, 60 e 50\%, respectivamente. Ambos caroços apresentam como principal ácido graxo insaturado o ácido linoléico (ômega-6) essenciais para a alimentação humana.

Tabela 1- Perfil em ácidos graxos das farinhas dos caroços de abacate, jaca e seriguela $(\% \mathrm{~m} / \mathrm{m})$

\begin{tabular}{lccc}
\hline $\begin{array}{c}\text { Ácidos Graxos } \\
(\% \mathrm{~m} / \mathrm{m})\end{array}$ & $\begin{array}{c}\text { Óleo de Abacate } \\
(\%)\end{array}$ & $\begin{array}{c}\text { Óleo de Jaca } \\
(\%)\end{array}$ & $\begin{array}{c}\text { Óleo de } \\
\text { Seriguela } \\
(\%)\end{array}$ \\
\hline (C 8:0) Caprílico & 0,47 & 0,89 & - \\
(C10:0) Caprico & 0,72 & 2,68 & 1,44 \\
(C 12:0) Láurico & 0,21 & 0,71 & 0,13 \\
(C 14:0) Mirístico & 0,48 & 2,14 & 0,30
\end{tabular}


(C 15:0) Pentadecilico

(C 16:0) Palmítico

(C 16:1) Palmitoléico

(C 17:0) Margárico

(C 17:1) cis-10-

heptadecenóico

(C 18:0) Esteárico

(C 18:1) Oléico

(C 18:2) Linoléico

(C 18:3) Linolênico

(C 20:0) Araquinidico

(C 22:0) Behenico

(C 24:0) Lignocérico

$\mathrm{NI}^{*}$

$\sum$ acidos graxos saturados

$\sum$ dos insaturados

${ }^{1}$ Média de três determinações

*NI: Não identificado.

** $\mathrm{O}$ alto teor de NI nessa amostra se deve a grande dificuldade da extração do seu óleo, arrastando interferentes.

Segundo MASSAFERA et al.(2010), avaliou a composição de ácidos graxos do óleo do caroço de cultivares de abacate (Persea americana, mill.) da região de Ribeirão Preto/SP e os resultados apresentaram com maior concentração o ácido oléico nos cultivares Fortuna e Ouro Verde (35,8\% e 18,7\%, respectivamente), enquanto que no cultivar Princesa foram o ácido palmítico e linoléico (32,0\% e 23,3\%, respectivamente). Em relação às concentrações dos ácidos palmíticos e oléico, os três cultivares apresentou diferença significativa $(\mathrm{p}<0,05)$. Enquanto que a concentração de ácido linoléico nos cultivares Ouro Verde e Princesa, foi maior do que o ácido oléico, quando comparado com o óleo do caroço das cultivares estudadas. Esses dados diferem em porcentagem aos encontrados nesse estudo, mas corroboram no perfil qualitativo.

Os dados obtidos pelos autores foram qualitativamente superiores se comparados com os resultados obtidos no presente trabalho (Tabela 1). No perfil de ácidos graxos dos caroços de abacate, jaca e seriguela se destacaram o ácido linoléico, portanto os resultados foram superiores se comparados com os resultados obtidos por SILVEIRA et al.(2014) considerando o solvente n-hexano.

A quantidade de ácidos graxos saturados do caroço de abacate (Tabela 1) apresentou maior valor quando comparado ao óleo extraído da semente de goiaba utilizando o solvente n-hexano citado por SILVEIRA et al.(2014). Com relação aos ácidos graxos insaturados os óleos de caroços de jaca e seriguela apresentaram resultados superiores (Tabela 1) quando comparados por SILVEIRA et al. (2014) usando como solvente o n-hexano.

\section{CONCLUSÕES}

O óleo do caroço de abacate apresentou maior concentração de ácidos graxos saturado quando comparado aos óleos resultantes de caroços de jaca e seriguela. Por outro lado, os óleos de jaca e seriguela apresentaram elevado percentagem de ácidos 
graxos insaturados. Destaca-se também que o ácido linoléico está presente em maior quantidade os caroços de jaca e seriguela e para farinha do caroço de abacate o ácido palmítico. As características dos óleos destes caroços podem ser utilizados como ingredientes na elaboração de produtos e dessa forma agregar valor desses materiais que normalmente são descartados.

\section{REFERÊNCIAS}

1.AOCS. American Oil Chemists Society. Official methods and recommended practices of the American Oil Chemists Society. $5^{\text {th }}$ ed. Champaign. USA, 2009.

2.BLIGH, E. G.; DYER, W.J. The National Research Council of Canada. Canadian Journal Biochemistry Physiology, v.37, n.8, p.912-913, 1959.

3.FILGUEIRAS, H. A.C.; MOURA, C. F. H.; ALVES, R. E. Seriguela (Spondias purpúrea L.).In: DONADIO, L.C.(ed.).Caracterização de frutas nativas da América Latina. Jaboticabal: Funep, 2000, cap 7, p.27.

4.HARTMAN, L.; LAGO, R. C. Rapid determination of fatty acid methyl esthers from lipids. Laboratory Practice. London, v.22, n.6, p.475-476, 1973.

5.MAIA, E. L. Otimização de metodologia para caracterização de constituintes lipídicos e determinação da composição em ácidos graxos e aminoácidos de peixes de água doce. 1992. 242p. Tese (Doutorado em Tecnologia de Alimentos)- Universidade Estadual de Campinas, Campinas, 1992.

6.MASSAFERA, G.; COSTA, T.M.B; DUTRA, O. J. E. Composição de ácidos graxos do óleo do mesocarpo e da semente de cultivares de abacate (Persea americana, mill.) da região de Ribeirão Preto, SP. Alimentos e Nutrição, Araraquara, v.21, n.2, p.325-331, 2010.

7.MAYSER, P.; MROWIETZ, U.; ARENBERGER, P.; BARTAK, P.; BUCHVALD, J.; CRISTHOPHER, E.; JABLONSKA, S.; SALMOHOFER, W.; SCHILL, W.B.; KRAMER, H.J.; SCHLOTZER, E.; MAYER, K.; SEEGER, W.; GRIMMINGER, F. $\omega-$ 3 fatty acid-based lipid infusion in patients with chronic plaque psoriasis: results of adouble-blind, randomized, placedo-controlled, multicenter trial. J. American Academy of Dermatology, v.38, n.4, p.539-547, 1998.

8.MELO, G. L.; VIEIRA, G.; ARAÚJO, A.; SOUZA, I.V DE.; LACERDA, T. Caracterização das propriedades físicas e físico-químicas da jaca in natura e desidratada. XII Seminário de Iniciação Científica da UESC . Ciências Agrárias, Anais, p.114-115, 2006.

9.NURAY, Z.U.; TORSTEN, B.; STEVEN, K.C.; STEVEN, J.S. Carotenoid absorption from salad and salsa by humans is enhanced by the addition of avocado or avocado oil. J. Nutrition, v.135, n.3, p.431-436, 2005.

10.ROCHA, E.M.; AGUIAR, S. F.; ARAÚJO, V.S.; DUARTE,W.K.C.; MAGALHÃES, M. M. Elaboração e caracterização de sobremesa láctea à base de frutas tropicais. Higiene Alimentar, v.19, n.129, p.12-14, 2005. 
11.SANDER, T. A. B. Polyunsatured fatty acids in the food chain in Europe. The American Journal of Clinical Nutrition, v.71, n.1, p.176-178, 2000.

12.TAKAHASHI, N. S. Importância dos ácidos graxos essenciais. Instituto de Pesca, 2005.1p.

13.WARD, O.P. Microbial production of long-chain PUFAs. Biotechnology Inform, v.6, p.683-687, 1995. 